\title{
Large-Scale Direct Shear Test on Scrap Tire Strip Reinforced Brick Powder
}

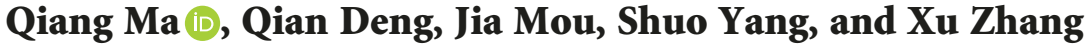 \\ Technology Research Center of Ecological Road Engineering, Hubei University of Technology, Wuhan 430068, China \\ Correspondence should be addressed to Qiang Ma; maqiang927@163.com
}

Received 9 October 2018; Revised 29 December 2018; Accepted 5 February 2019; Published 3 March 2019

Academic Editor: Hui Yao

Copyright (c) 2019 Qiang Ma et al. This is an open access article distributed under the Creative Commons Attribution License, which permits unrestricted use, distribution, and reproduction in any medium, provided the original work is properly cited.

In order to clear the shear mechanism of the scrap tire strips reinforced brick powder, a series of large-scale direct shear tests were carried out on the pure brick powder and reinforced brick powder. The scrap tire strips with $50 \mathrm{~mm}$ in length, $5 \mathrm{~mm}$ in thickness, and $10 \mathrm{~mm}, 30 \mathrm{~mm}$, and $50 \mathrm{~mm}$ in width were put into the brick powder with volume percentages of $2 \%, 6 \%$, and $10 \%$ as reinforcement, respectively. The results show that the internal friction angle and cohesion increase by adding scrap tire strips into brick powder. The peak shear strength of reinforced brick powder initially decreases, thereafter increases and finally decreases with the increase of volume percentage of the scrap tire strips. And the peak shear strength increases in the initial stage and then decreases with the increase of the scrap tire strips dimension. The optimal dimension and volume percentage of the scrap tire strips are $50 \mathrm{~mm} \times 30 \mathrm{~mm} \times 5 \mathrm{~mm}$ and $6 \%$, respectively. In addition, the scrap tire strips provide constraints to restrict the vertical displacement of integral reinforced brick powder, and relative to the pure brick powder, the larger the vertical load is, the greater the decrease of vertical displacement is.

\section{Introduction}

The rapid development of automobile industry produces a large number of scrap tires, which brings great pressures to resources and environment. At present, the main ways of recycling scrap tires are retreading, rubber powder, reclaimed rubber, thermal energy utilization, pyrolysis, and so on [1-3]. Furthermore, the characteristics of scrap tires are toughness, strong plasticity, stable structure in nature, and not easy to break and decompose $[4,5]$. It is because of these properties that scrap tires are clarified as an excellent reinforcing material $[6,7]$. To date, there has been a series of studies on the scrap tires composite soil by scholars; in order to study the scrap tire mechanical performance more in detail, the scrap tire has been divided into three kinds of reinforcing shapes, tire-ring, tire particle, and tire strip.

One common form of scrap tires reinforcement was the tire-ring reinforcement. Through the plate load tests, it was presented that the foundation enhancement effect of adding the tire mat combined with treads and sidewalls of tires was effective under various conditions, such as embedded depth, number of reinforced layers, size of tire mat, and combination type of tire segments. And it was a reference for tire reinforcement research [8]. In field tests, the effects of the load levels and the number of tires on the overall tensile properties of the tire-ring unit were discussed. The ultimate tensile strength of the tire-ring unit was explored, and it was approximately 1.25 times that of the geocell, which would be used in the design and construction of reinforced brick powder structures [9]. And by the tire-reinforced slope model test, it could be concluded that, after adding the tirering, the additional stress near the tire was significantly reduced and the overall settlement of the embankment was diminished [10]. Although there were some achievements of tire-ring reinforcement on the overall displacement, the uneven stress distribution between tire-ring and soil would be an uncontrollable factor. Accordingly, because of its limited application area, the tire-ring reinforcement has not been widely used. Another general form of tire reinforcement was the tire particle reinforcement. Tafreshi and Norouzi [11] studied the bearing capacity of foundation with tire particle and crushed stone through the model tests. It 
was concluded that the bearing capacity of the tire particles reinforced soil was greatly affected by the amount of tire particles, the thickness of reinforced soil, the optimum particles size, and soil thickness. Zheng et al. [12] summarized the mechanism and improvement effect of different tire particle sizes in pavement asphalt, cement concrete, and clay. It was found that the service performance and service life of asphalt were improved, the shear strength of sandy soil was enhanced, and the cohesion and permeability of clay were increased. He et al. [13] investigated the strength of tire powder mixed clay through the strength test, and it was proposed that the strength was increased with the increase of the rubber-mixing ratio. Because of the stress redistribution in the reinforcement, the stress was uniformly distributed in the soil, and it was not easy to exceed the bearing capacity of the reinforced soil in real life. Therefore, the further investigations of tire particles reinforcement need to be done. Another normal form of the tire reinforcement was the tire strip. Foose et al. [14] tested that the shear strength and resistance to deformation of sand were effectively improved by adding tire strip. Ghazavi and Sakhi [15] obtained the variation laws of shear strength and the deformation properties of mixed sand through a large-scale direct shear test, which changed the tire strip sizes and contents in sand. Hataf and Rahimi [16] carried out a series of model tests to explore the impact of different tire strip contents, and the results illustrated that the bearing capacity of sand could be improved by the tire strip. Mixing tire strip into sand, it would not only exert the interaction between tire strip and sand but also increase friction to limit the displacement of sand and maintain its overall stability. To do that, Youwai and Bergado [17] created a constitutive model of tire stripsand mixture by the finite element method. It was established to verify the bearing capacity of the reinforced soil. Therefore, the tire strip reinforcement is more prevailing. Hazarita et al. [18] studied the reinforcing deformation mechanism of tire fragments used as reinforcement materials for soil improvement through direct shear and triaxial shear tests using X-ray computed tomography. It was found that the shear strain of tire fragments mixed in sand was smaller than that of pure sand. And it was also found that it was difficult to liquefy the mixture of tire fragments and sand if the appropriate mixing percentage was used. Therefore, tire fragments can be successfully used as reinforcement to help prevent liquefaction of sandy soil.

Moreover, with the rapid development of urban construction in the world, a lot of construction waste has been generated. The construction industry is the most important contributor to the total amount of the industrial waste. The total industrial waste accounts for $50 \%$ of the world's natural resources consumption [19]. Using construction waste to fill roadbed and subbase of pavement could effectively reduce the area occupied by construction waste and the environmental pollution caused by long-term stacking. Recently, Settari et al. [20], Martínez et al. [21], Zhang et al. [22], and Rosalía et al. [23] studied the performance of construction waste as embankment backfill from different perspectives and concluded that construction waste had good performance as roadbed filling. And before that, through the laboratory and field studies, Park [24] indicated that the characteristics and performance of the recycled aggregate added scrap tire were considered. Then, it was turned that the recycled aggregate with scrap tire could replace macadam aggregate as the filling material of the base course and the subbase for road. The stability and shear strength were higher than macadam aggregate under dry condition. In order to verify the feasibility of using construction waste as paving material for pavement base, Herrador et al. [25] analyzed the characteristics of the recycled aggregate from construction waste under actual vehicle traffic conditions by in situ tests. It was shown that the bearing capacity of the recycled aggregate from construction waste could meet the requirements of pavement base. Jiménez et al. [26] evaluated the behavior and the environmental impact of the recycled aggregates from the selecting construction waste by the field test. And the deformation of the pavement was monitored by a deflectometer, and the results showed that the recycled aggregates from construction waste could be an alternative material in the unpaved rural road without risk of environmental pollution. Through the model test, Delongui et al. [27] studied the strength and the stressstrain characteristics of the recycled aggregate to obtain pavement design parameters. The test results illustrated that the approximate elastic response was in the recycled aggregate. And its deformation resistance was better than the traditional fine aggregate; thus, it could be used in the construction of urban road base. Therefore, all these studies show that adding scrap tires into construction waste to form reinforcement can improve the global strength, and it absorbs two kinds of solid waste at the same time, which has good economic, social, and ecological benefits.

Generally, the study on scrap tires and construction waste has been more extensive, while the research on mechanical properties of scrap tires reinforcement is relatively less. Thus, large-scale direct shear tests were carried out to investigate the optimum stiffening rate and size of the tire strips with different stiffening ratios and sizes. In addition, the working mechanism of the tire strip reinforced brick powder was studied to provide reference for the application of the scrap tires reinforced construction waste.

\section{Test Apparatus and Material}

2.1. Test Apparatus. As shown in Figure 1, the ZY50-2G large-scale direct shear testing instrument developed by Chengdu Donghua Excellence Technology Ltd. is employed to carry out the tests. The instrument mainly consists of shear apparatus, displacement sensors, and data acquisition system. The shear apparatus is divided into the upper and the lower shear boxes, and the lower box is fixed while the upper can be disassembled, and the diameter of the shear box is $504.6 \mathrm{~mm}$.

2.2. Test Material. The construction waste used in the test is the crushed brick, and the mass percentage of particles less than the particle size curve is shown in Figure 2.

The test tires are the scrap tires of standard car named as model 145/70R12 (the tread width was $145 \mathrm{~mm}$, the flat ratio 


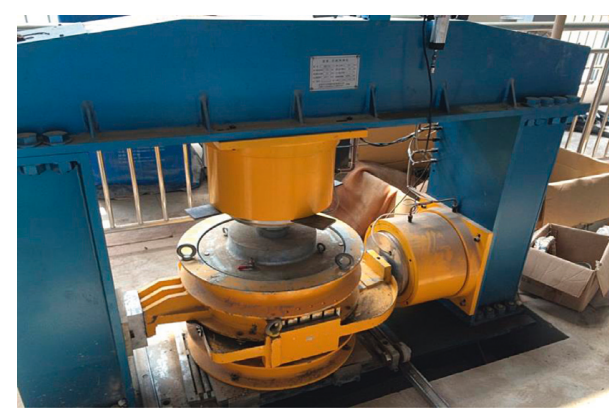

FIGURE 1: Direct shear testing instrument.

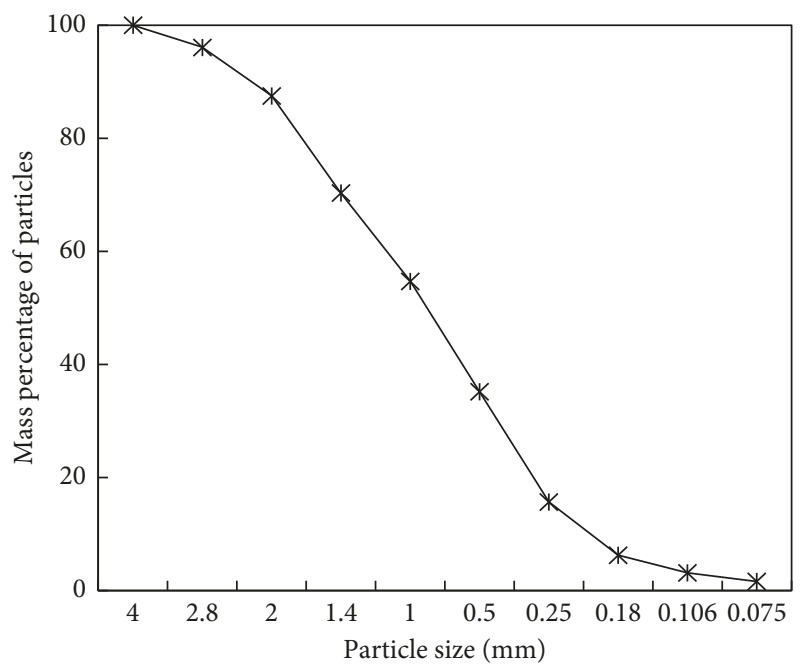

FIGURE 2: Curve of brick powder grading.

was $70 \%$, and the diameter was 12 inches, i.e., $30.48 \mathrm{~cm}$ ). The scrap tires were divided to strips with $50 \mathrm{~mm}$ in length and $10 \mathrm{~mm}, 30 \mathrm{~mm}$, and $50 \mathrm{~mm}$ in width, respectively. Table 1 shows the tire parameters.

\section{Test Procedure and Results}

3.1. Test Procedure. In the test, strain controlled direct shear apparatus were adopted, and the shear rate was controlled at $0.5 \mathrm{~mm} / \mathrm{min}$. By the controlling variable method, the shear mechanical properties of shredded tire strips to reinforce brick powder were studied, and the influence of different volume percentage and size on the shear performances of scrap tires was discussed.

The scrap tire strips were uniformly added to the brick powder to make them randomly distributed. The influencing factors of the reinforcing material were analyzed by controlling the volume percentage and the width of the tire. And the volume percentage was $0,2 \%, 6 \%$, and $10 \%$ [11], and the width was $10 \mathrm{~mm}, 30 \mathrm{~mm}$, and $50 \mathrm{~mm}$, respectively. The direct shear tests were carried out under seven different normal pressures of $50 \mathrm{kPa}, 100 \mathrm{kPa}, 200 \mathrm{kPa}, 400 \mathrm{kPa}$, $800 \mathrm{kPa}, 1200 \mathrm{kPa}$, and $1600 \mathrm{kPa}$ for each group of specimens with different volume percentages and sizes.

The moisture content of the mixture was controlled at about $15 \%$ after mixing scrap tire strips and brick powder
TABLE 1: Parameters of scrap tire strips.

\begin{tabular}{lccc}
\hline $\begin{array}{l}\text { Relative } \\
\text { density }\end{array}$ & $\begin{array}{c}\text { Thickness } \\
(\mathrm{mm})\end{array}$ & $\begin{array}{c}\text { Tensile strength } \\
\left(\mathrm{kN} / \mathrm{m}^{2}\right)\end{array}$ & $\begin{array}{c}\text { Elastic modulus } \\
\left(\mathrm{kN} / \mathrm{m}^{2}\right)\end{array}$ \\
\hline 1.2 & 5 & 1230 & 24500 \\
\hline
\end{tabular}

smoothly, and then, the specimens were loaded when the moisture content was stable. The quality of each specimen was $135 \mathrm{~kg}$. It was compacted through 3 layers, and each layer was compacted to the same height to control the compaction degree of the specimen, and the diameter of the specimen was $504.6 \mathrm{~mm}$, and the height was $400 \mathrm{~mm}$ finally; the process of sample preparation is shown in Figure 3. In the test, vertical load of the specimen was applied firstly, and the horizontal shear force was added after the stabilization of the vertical load. Horizontal displacement of the lower shear box was driven by horizontal hydraulic press. When the shear failure was achieved or the shear displacement of the specimen reached $60 \mathrm{~mm}$, the shear of the specimen should be stopped.

\subsection{Test Results}

3.2.1. Shearing Behavior. To explore the effect of the reinforcement ratio of tire strip on the shear properties of brick powder, under vertical loads of $50 \mathrm{kPa}, 100 \mathrm{kPa}, 200 \mathrm{kPa}$, and $400 \mathrm{kPa}$, the shear stress-shear displacement relationship of brick powder is shown in Figure 4.

When the vertical load was $50 \mathrm{kPa}, 100 \mathrm{kPa}, 200 \mathrm{kPa}$, and $400 \mathrm{kPa}$, the shear stress-shear displacement curves were softening. It showed that the shear stress increased with the increase of shear displacement and then decreased after reaching the peak value. Moreover, the shear stress and its peak value increased with the increase of the vertical load. When the shear displacement was small, the slopes of shear stress-shear displacement curves under different vertical loads had little difference; however, the slopes increased gradually with the increase of the shear displacement. The results indicate that the influence of vertical load on the shear stress of the specimen is more significant when the shear displacement is large.

Figure 4(b) shows that the peak shear stress increased with the increase of vertical load when the vertical load was $50 \mathrm{kPa}, \quad 100 \mathrm{kPa}, 200 \mathrm{kPa}$, and $400 \mathrm{kPa}$, respectively. Compared with the pure brick powder sample in Figure 4(a), the increasing ratios were $-24.8 \%,-3.2 \%$, $4.2 \%$, and $6.5 \%$, respectively. When the vertical load was $50 \mathrm{kPa}$ and $100 \mathrm{kPa}$, the shear strength of the specimens was slightly reduced. When the vertical load was $200 \mathrm{kPa}$ and $400 \mathrm{kPa}$, the peak shear stress increased by $4.2 \%$ and $6.5 \%$. The tire strip had the best reinforcing effect when the vertical load was $400 \mathrm{kPa}$. Figure 4(c) shows that the peak shear stress increased by $-11.7 \%, 4.7 \%, 13.4 \%$, and $23.7 \%$, respectively, under vertical loads of $50 \mathrm{kPa}, 100 \mathrm{kPa}$, $200 \mathrm{kPa}$, and $400 \mathrm{kPa}$ compared with pure brick powder. Compared with $2 \%$ reinforcement ratio, the peak shear stress of $6 \%$ reinforcement ratio was higher under all levels of vertical loads. Figure $4(\mathrm{~d})$ shows that the increases of 


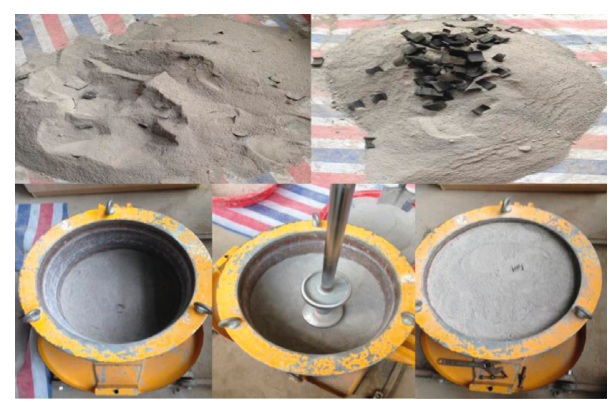

FIgURE 3: Sample preparation process.

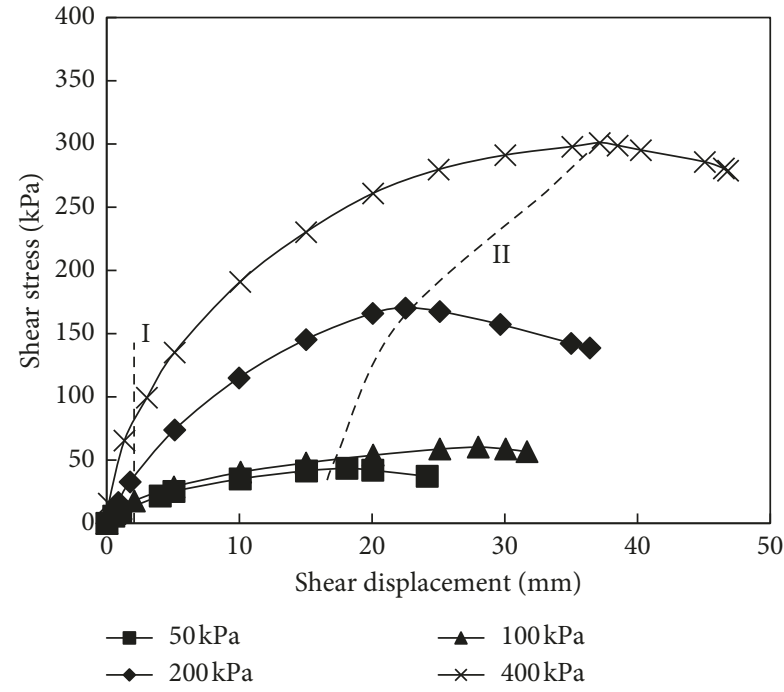

(a)

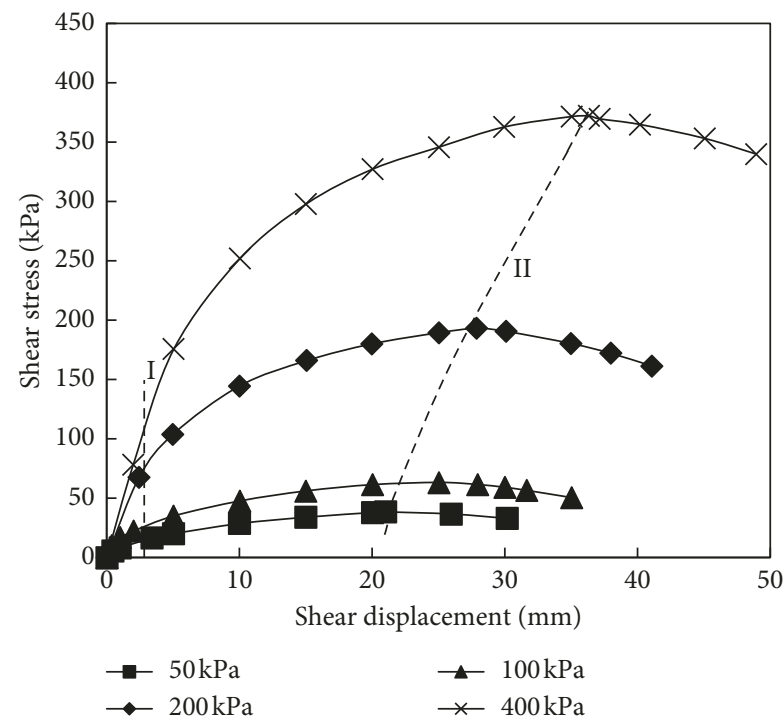

(c)

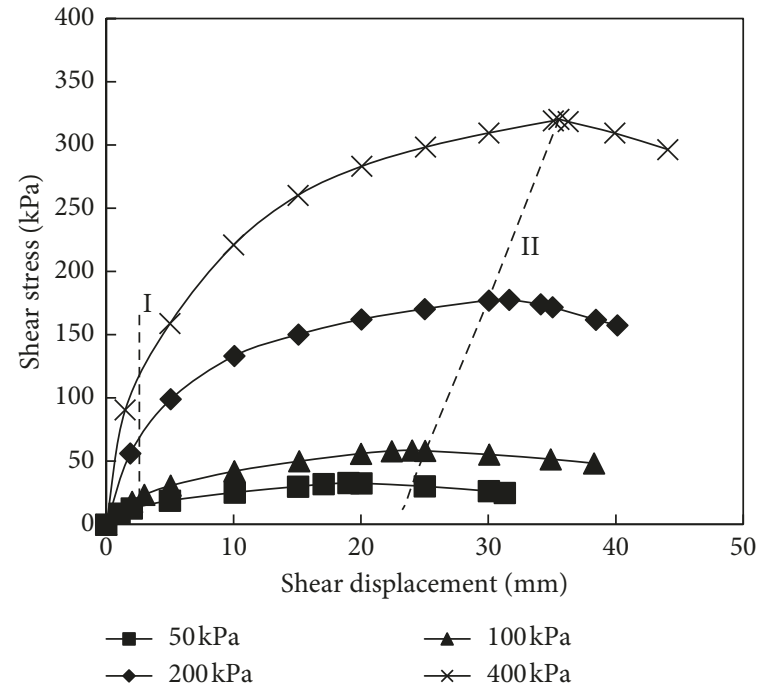

(b)

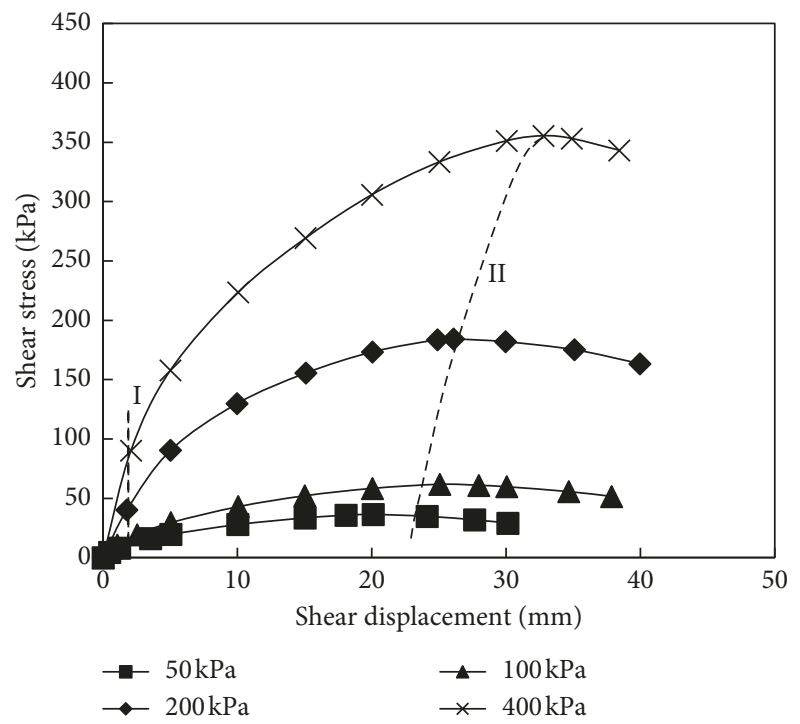

(d)

FIGURE 4: Shear stress-shear displacement of brick powder. (a) $0 \%$ rate of reinforcement. (b) $2 \%$ rate of reinforcement. (c) $6 \%$ rate of reinforcement. (d) $10 \%$ rate of reinforcement.

peak shear stress of specimens with $10 \%$ tire strips were $-16.4 \%, 2.4 \%, 8.1 \%$, and $18.1 \%$, respectively, under vertical loads of $50 \mathrm{kPa}, 100 \mathrm{kPa}, 200 \mathrm{kPa}$, and $400 \mathrm{kPa}$. Compared with Figures $4(\mathrm{a})-4(\mathrm{c})$, the results showed that the reinforcement rate of $10 \%$ was better than the reinforcement rate of $2 \%$, and the reinforcement rate of $6 \%$ was the best. 
Under the vertical load of $50 \mathrm{kPa}$ and $100 \mathrm{kPa}$, the reinforcing effect of different reinforcement ratios was poor. The possible reason is that the compaction degree of the brick powder is low when the vertical load is small. Because the relative motions occur between particles during shearing, the added scrap tire strips form a "suspension structure" in the brick powder which reduces the friction between the particles. And the radian of the tires is natural; so, the addition of the tire strip will generate the holding force in the reinforcement. Furthermore, when the friction between the particles is greater than the holding force, the shear strength will be reduced, and the reinforcement effect will be poor. In addition, the reinforcing effect under vertical loads of $200 \mathrm{kPa}$ and $400 \mathrm{kPa}$ is significantly superior to that of under $50 \mathrm{kPa}$ and $100 \mathrm{kPa}$.

To clarify the shear mechanical characteristics of the brick powder under big vertical loads, large-scale direct shear tests were carried out under vertical loads of $800 \mathrm{kPa}$, $1200 \mathrm{kPa}$, and $1600 \mathrm{kPa}$, respectively. The results are shown in Figure 5.

Figure 5 shows that the peak value of shear stress increased after the specimen is added with tire strips, and it increased and then decreased with the increase of the reinforcement ratio. Compared with pure brick powder, the peak shear stress of specimens increased $6.5 \%, 23.7 \%$, and $18.1 \%$ at $400 \mathrm{kPa}$, respectively. It increased $1.3 \%, 10.3 \%$, and $6.9 \%$ at $800 \mathrm{kPa} ;-1.7 \%, 8.4 \%$, and $1.93 \%$ at $1200 \mathrm{kPa}$; and $-2.8 \%, 2.1 \%$, and $0.85 \%$ at $1600 \mathrm{kPa}$. Thus, the reinforcement ratio of $6 \%$ at $400 \mathrm{kPa}$ of the vertical load had the optimized reinforcement effect in the tests.

Figures 4 and 5 include three different stages of the shear stress-shear displacement curve about tire strip reinforced brick powder: (1) in the elastic stage (before the (I) in the curve), the segment of the shear stress-shear displacement curve approximates a straight line, which illustrates that, when the shear displacement is relatively small, the internal structure of the reinforced brick powder is stable because of the close combination between tire strips and the brick powder, and the holding force of the tire strip will exert on the surrounding brick powder. At the same time, the scrap tire strips play a tensile role in the test. Both of these effects gradually increase with the increase of shear displacement. (2) In the yield stage (between (I) and (II) in the curve), the slope of the curve becomes smaller. It illustrates that, when the shear displacement increases to a certain value, the tensile strength of the tire strip in the test will be fully played, and the force of the tire surface will slowly become smooth during the shear process. With the radian decreases on the tire strips, the holding force will be also decreased. (3) In the softening stage (after (II) in the curve), the relative displacement of the reinforced brick powder interface is occurred. At this moment, a part of the strength at the interface has been exceeded, so the tensile strength, the holding force, and the shear stress of the reinforced brick powder decreases, and the tire strip becomes depressed.

When the vertical load is relatively small $(50 \mathrm{kPa}$ and $100 \mathrm{kPa}$ ), the compaction degree of the brick powder is low. And it forms a "suspension structure" in the brick powder particles after adding tire strip. The tire strip acts as a lubricant, reducing the friction between the brick powder particles. In addition, it generates holding force inside the reinforced brick powder after adding the tire strip. The holding force will limit the lateral deformation and displacement of the brick powder to some extent. However, when the friction between particles is greater than the holding force, the shear strength will be weakened; so, the effect of reinforcement is not obvious under lower normal force.

When the vertical load is big (1200 kPa and $1600 \mathrm{kPa})$, the brick powder particles are tightly combined to form a whole. When the tire strip is added, internal friction will be increased, and the tire strip acts as a coating on the brick powder. At this time, the tire strips also exert a holding force on the specimen, so the integrity of the specimen is affected by adding the tire strip locally. The integrity of the specimen is destroyed, and there is a lost part of the friction force, which is greater than the holding force. In particular, under the extremely high normal force $(1600 \mathrm{kPa})$, the brick powder is pressed into blocks, which leads to a decline in the integrity of the material. Therefore, the peak value of the shear force is smaller at the reinforcement ratio of $2 \%$ than that of no reinforcement; moreover, under high vertical load, the growth rate of peak strength is not obvious.

Comparing with pure brick powder, when the normal force was small $(50 \mathrm{kPa}, 100 \mathrm{kPa}$, and $200 \mathrm{kPa})$, there was no significant difference in the maximum vertical displacement of the reinforcement specimens. When the vertical load was greater than or equal to $400 \mathrm{kPa}$, the maximum vertical displacement of the stiffened specimen decreased, and the maximum vertical displacement of the stiffened specimen increased with the increase of the vertical load and the reinforcement ratio. Under higher normal forces $(400 \mathrm{kPa}$, $800 \mathrm{kPa}, 1200 \mathrm{kPa}$, and $1600 \mathrm{kPa}$ ), the maximum vertical displacement after reinforcement was significantly smaller than that without reinforcement. The vertical loaddisplacement curve of pure brick powder and $6 \%$ of reinforcement ratio is shown in Figure 6.

Figure 7 shows the shear stress-shear displacement curve of different widths on the tire strip when the reinforcement ratio is $6 \%$.

Figure 7 shows that the peak shear stress of the tirereinforced brick powder increased and then decreased with the increase of the tire width. Compared with the pure brick powder, the growth of the peak shear stress was the best at $400 \mathrm{kPa}$. And the width of $10 \mathrm{~mm}, 30 \mathrm{~mm}$, and $50 \mathrm{~mm}$ increased by $9.8 \%, 23.7 \%$, and $16.6 \%$, respectively. When the width of tire strip was $30 \mathrm{~mm}$, the peak shear stress of reinforced brick powder increased the most, and the reinforcement effect was the best.

Because the number of tire strips varies with the width of the tire, when the width is at $10 \mathrm{~mm}$, the tires are thin and numerous, and the distribution is random, so the holding force is weak. When the width is at $30 \mathrm{~mm}$, each surrounding of the tire strip can be considered as a domain parcel. The holding force and friction between tire and brick particles in a single domain form a whole. There will also be interaction between parcels. At this time, the total increase of the 


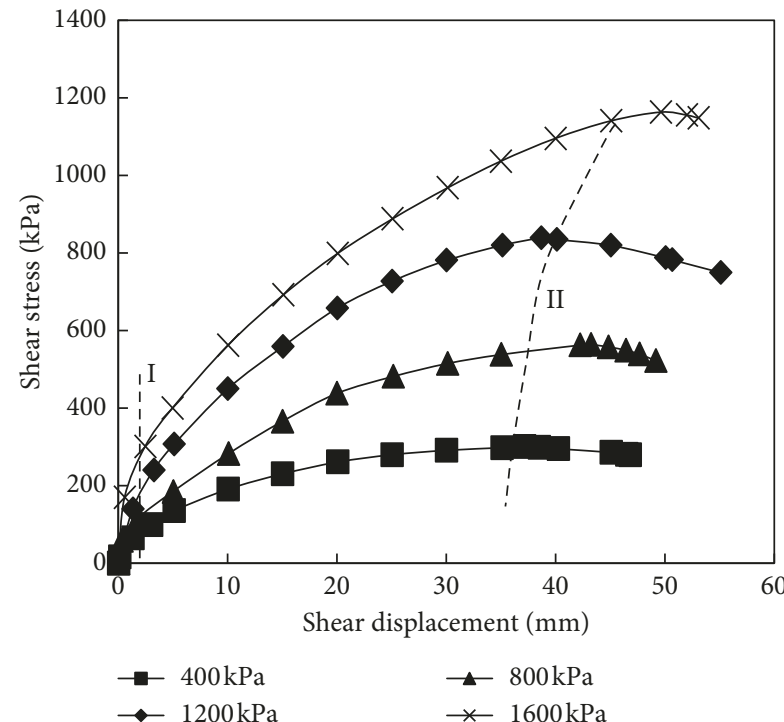

(a)

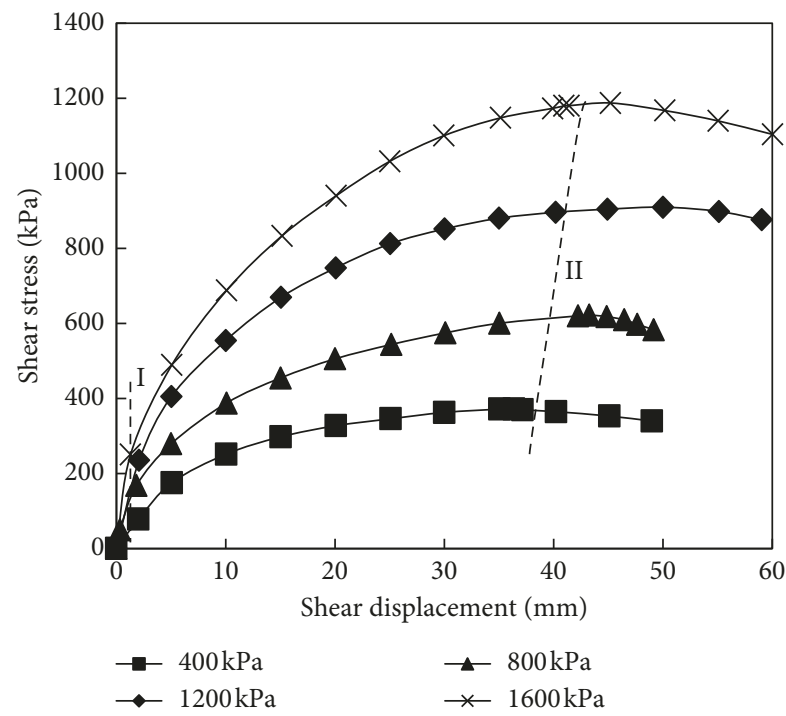

(c)

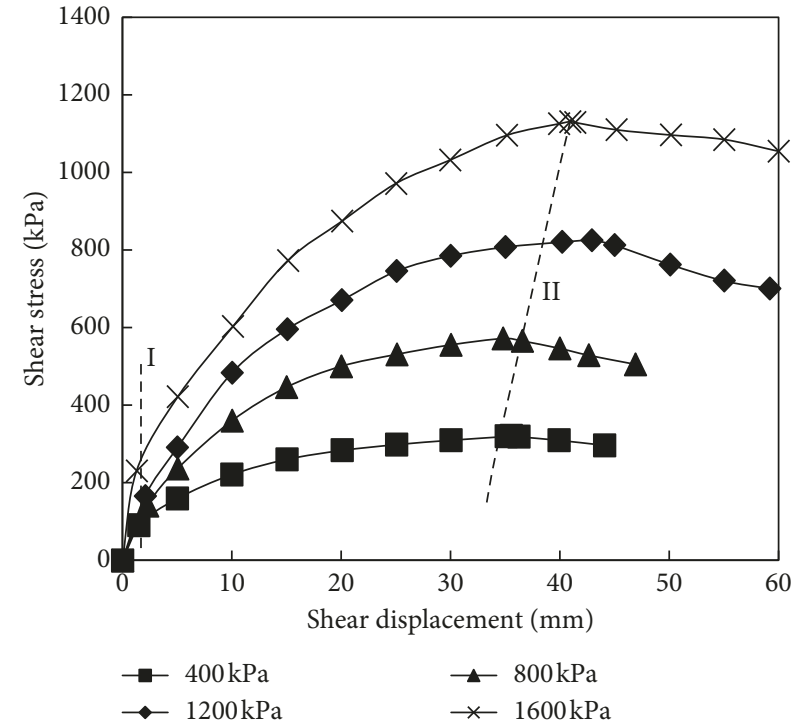

(b)

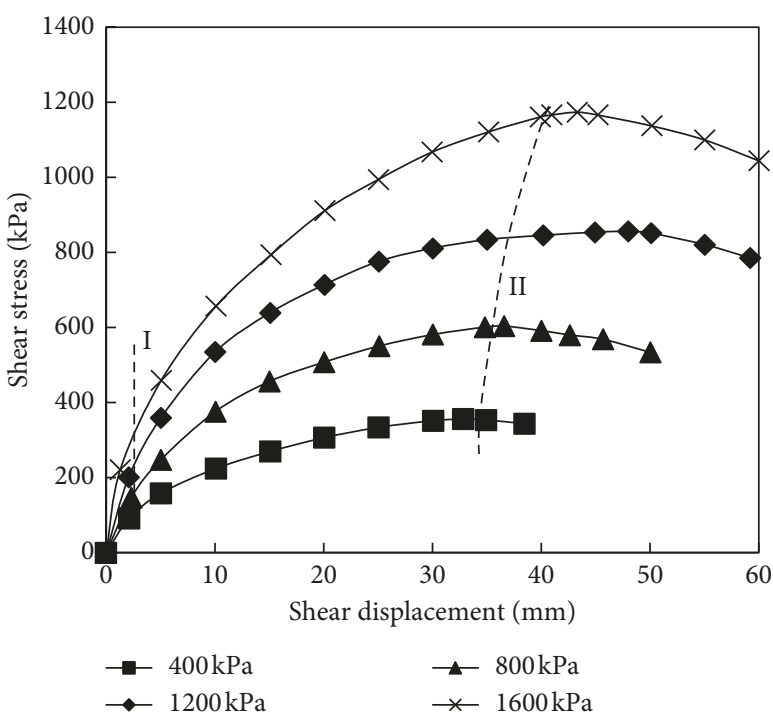

(d)

FiguRE 5: Shear stress-shear displacement curve of brick powder under high normal pressure. (a) $0 \%$ rate of reinforcement. (b) $2 \%$ rate of reinforcement. (c) $6 \%$ rate of reinforcement. (d) $10 \%$ rate of reinforcement.

holding force and friction within the reinforced brick powder increases the most, so the reinforcement effect is the best. When the width is at $50 \mathrm{~mm}$, the tire strip can provide more holding force to the particles, but the parcel of each tire strip is not closely linked, and "suspension structure" between the tire strip and brick powder particles is formed, and the tire strip brings less total force to the reinforcement than the $30 \mathrm{~mm}$. Hence, analyzing about it, the length should be uniformly $50 \mathrm{~mm}$.

The brick powder used in this test has strong compressibility while it is in elasticity. The compression modulus and strain of the tire strip are different from that of the brick powder. Therefore, the tire strip can produce a certain constraint to restrict the vertical displacement of the reinforcement, which has a certain weakening effect on the vertical displacement.
3.2.2. Influence on Shear Strength Parameters. Figure 8 describes the shear strength parameters of the reinforced brick powder with different reinforcement ratios and different tire sizes.

Figure 8(a) illustrates that the cohesion of the reinforced brick powder with tire strips increased and then decreased with the increase of the reinforcement ratio, and it reached the maximum when the reinforcement ratio of the tire strip is $6 \%$. At this point, compared with the pure brick powder, the variation of the cohesion was also the greatest. Meanwhile, the change of the internal friction angle was not obvious, which was in the range of $34.8^{\circ}$ to $36.3^{\circ}$. The results showed that the cohesion of the brick powder increased obviously with the reinforcement ratio of the tire strip, but the internal friction angle did not change much when the tire strip was added into the brick powder. When the 


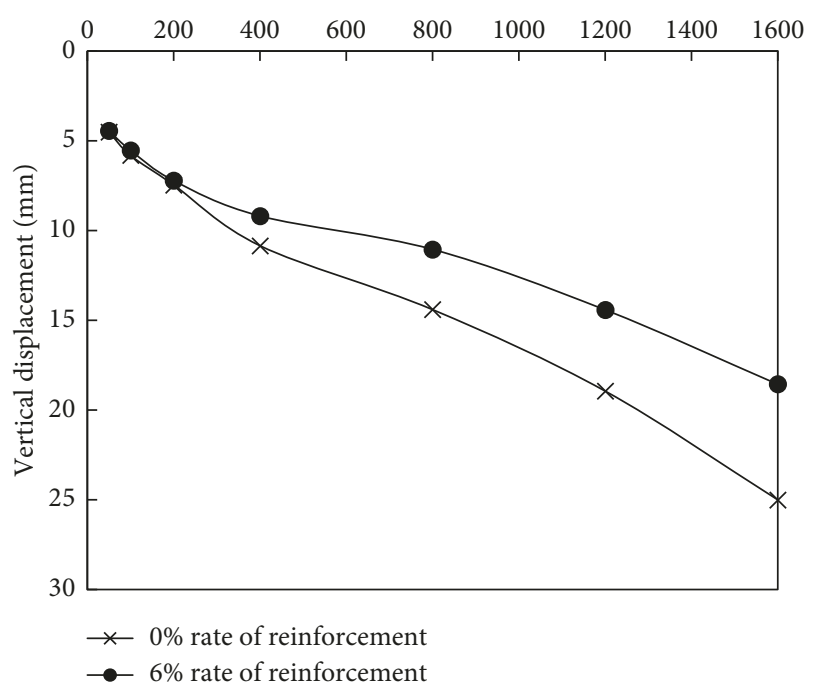

FIgURE 6: Vertical load-displacement curve.

reinforcement ratio was 0 , the cohesion of pure brick powder was $6.4 \mathrm{kPa}$. The probable reason is that the surface of the particles is irregular, when the relative displacement of particles occurs, particles are embedded within particles, and thus the interlocking force can be regarded as cohesive. Figure 8 (b) shows that the width of the tire strip only had a little influence on the internal friction angle that varied from $35.2^{\circ}$ to $36.3^{\circ}$. And the cohesion of reinforcement waved greatly with the width of the tire strip. At the width of $30 \mathrm{~mm}$, the cohesion reached $26.7 \mathrm{kPa}$, and it increased by $20.3 \mathrm{kPa}$ compared with $6.4 \mathrm{kPa}$ of pure brick powder. The results indicate that the influence of the reinforcement ratio and tire strip size on the shear strength of the specimens is mainly reflected in the effect on cohesion.

\subsubsection{Analysis of Optimal Reinforcement Ratio and Width.} Figure 8 indicates that the influence of the tire strip reinforcement ratio on the shear strength of the specimen increases first and then decreases. Combined with Figures 4 and 5, it can be seen that the reinforcement effect of the brick powder with scrap tire strips is the most significant at the reinforcement ratio of $6 \%$. The reason is that the effect between the tire strips and the brick powder is limited due to the small amount of the tire strips, so the contribution of the "suspension structure" to friction and holding force is insufficient in the reinforcement. And the "suspension structure" is composed of the tire strips and the brick powder. With the increase of the amount of tire strips, the internal friction and holding force of the specimen also increases. It shows that the peak shear strength of the reinforced powder increases with the increase of the reinforcement ratio. The reinforcement effect reaches a peak at the reinforcement ratio of $6 \%$, continuing to increase the volume percentage of the tire strip; the excessive tire strip cannot fully contact with brick powder, and the holding force cannot be displayed sufficiently. In addition, the excessive tire strips break the integrity of the reinforcement, which results in the decrease of the shear strength.
Combined with Figures 7 and 8, it can be found that the influence of the tire strip width on the shear strength increases first and then decreases. The optimal width is $30 \mathrm{~mm}$. The reason is that the number of tire strips varies with the width when the volume is constant. And when the size is $30 \mathrm{~mm} \times 50 \mathrm{~mm}$, the number of tire strip is appropriate. There are closely connected parcels of each tire strip. At this moment, the additional holding forces and frictions in the reinforcement increase the most, so the reinforcing effect is the best.

\section{Reinforcing Mechanism of Tire Strip}

The reinforcing mechanism of reinforced materials is to coordinate the deformation between the reinforcement and the surrounding brick powder, and to restrict the lateral deformation of the specimen by providing the additional friction in the interface of the reinforced materials and the surrounding fill, so as to achieve the purpose of reinforcement. At present, the principle of frictional reinforcement and cohesion concept based on limit equilibrium and limit state theory is commonly used to describe the reinforcing mechanism of reinforced soil $[28,29]$. Based on the principle of friction stiffening, the reinforcing mechanism of the tire strip reinforced brick powder can be explained by the mechanism of friction stiffening and bending [30]. The friction reinforcing mechanism is that the internal and external textures of the tire strip will produce friction with brick powder. With the increase of vertical load, brick powder particles will produce relative displacement under external load. At the same time, the particles will also be extruded, broken, and embedded. And when the brick powder is loaded, the interspace between particles will decrease, and the cohesion between particles will increase. The bending mechanism refers to the wrapping force exerted on the brick powder due to the natural curvature of the tire strip, which will produce the wrapping force of the tire on the concave side of the bending of the tire strip; then, it has a reinforcing effect. Tire strips and brick powder after compaction are photographed, see Figure 9.

Increasing the vertical load can make the interaction between the tire strip and the brick powder more fully increase the internal friction and wrapping force of the specimen, restrain the relative slip between the brick powder and the tire strip, limit the lateral deformation and displacement of the tire strip and the brick powder, improve the shear strength, and have a reinforcing effect. Changing the width of the tire strip makes the number of tire strips different. When the tire strip is narrow, the wrapping effect is weak. When increasing the width of the tire strip, the wrapping effect of the tire strip is strengthened. When the width of the tire strip exceeds its length, the reinforcement area of each tire strip will interact with each other, and it will form the "suspension structure" between the tire strip and the powder particles, and the reinforcing effect of the tire strip is reduced. Therefore, the peak shear stress of the tirereinforced soil increases and then decreases with the increase of the tire strip width. Additionally, the tire strips are 


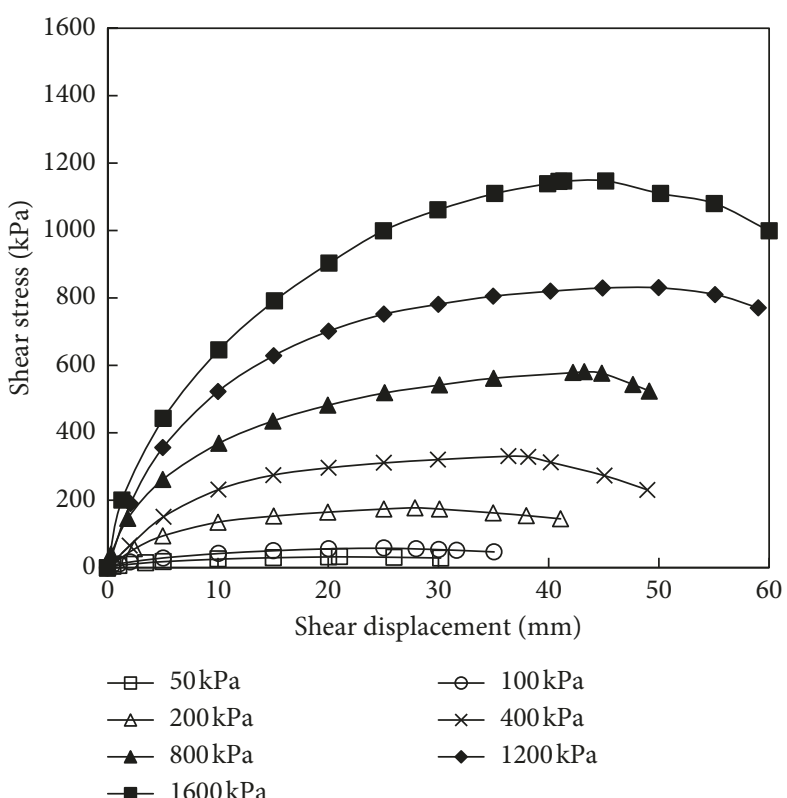

(a)

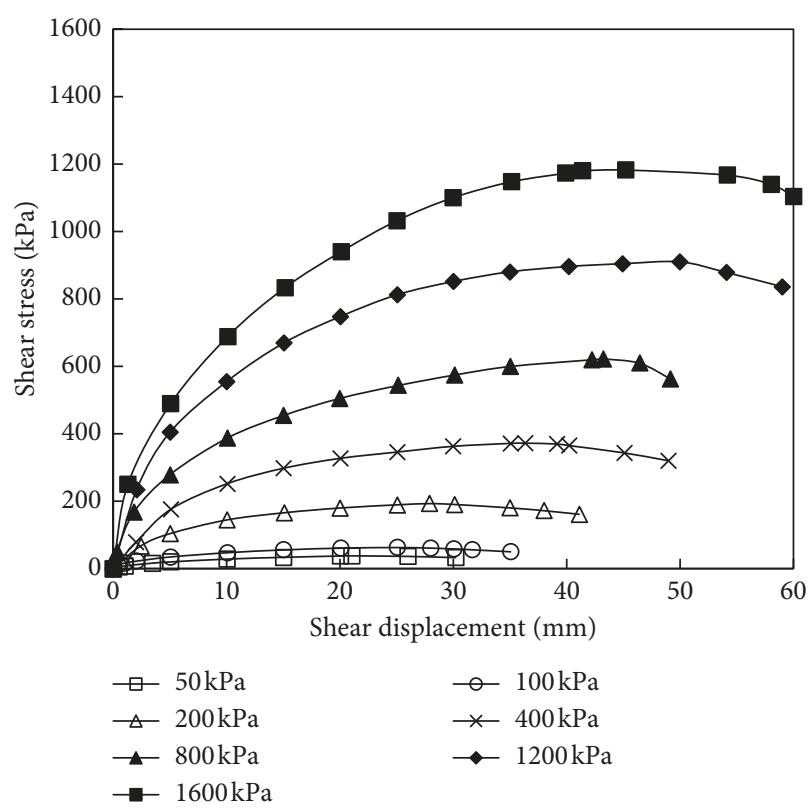

(b)

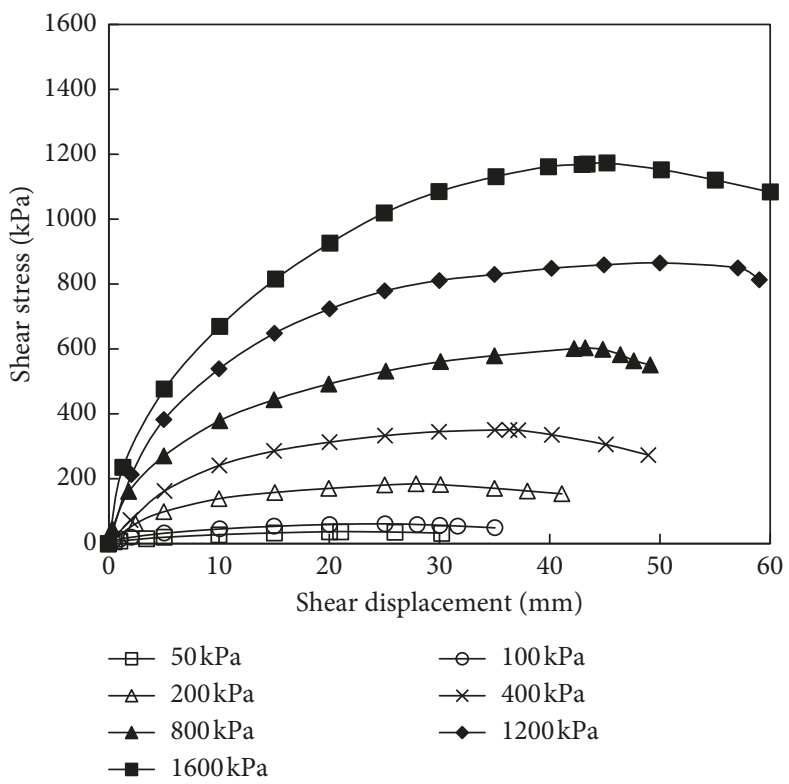

(c)

Figure 7: Shear stress-shear displacement curve of different tire specimen sizes at $6 \%$ reinforcement ratio. (a) $10 \mathrm{~mm} \times 50 \mathrm{~mm}$. (b) $30 \mathrm{~mm} \times 50 \mathrm{~mm}$. (c) $50 \mathrm{~mm} \times 50 \mathrm{~mm}$.

randomly distributed and interwoven, the bended tires interweave with each other, and the interweaving areas increase with the increase of the volume percentage of the tire strip, thus weakening the reinforcing effects.

After loading, relative displacements between particles appeared, and the change of tire strips reinforced brick powder subjected to external load is as shown in Figure 10.

When adding the tire strip to the brick powder, it not only increased the internal friction of the reinforcement but also exerted the wrapping effect on the particles, because of the radian of the tire strip and the stripes on the tire strip surface. With the increase of vertical load, the brick powder particles produced relative displacement, and the particles would be extruded, broken, and interlocking. When the relative motion of the brick powder particles was completed, the tire and brick powder particles with irregular surface would have interlocking effect. The interlocking effect increased the friction and cohesion between the tire and brick powder, and the breakage of the brick particles filled and reduced the interspace between the tire and brick powder, and the bonding of brick powder particles would be closer and closer. Consequently, when subjected to external loads, the tire strips reinforced brick powder represented an increased friction and a reduced interspace. 


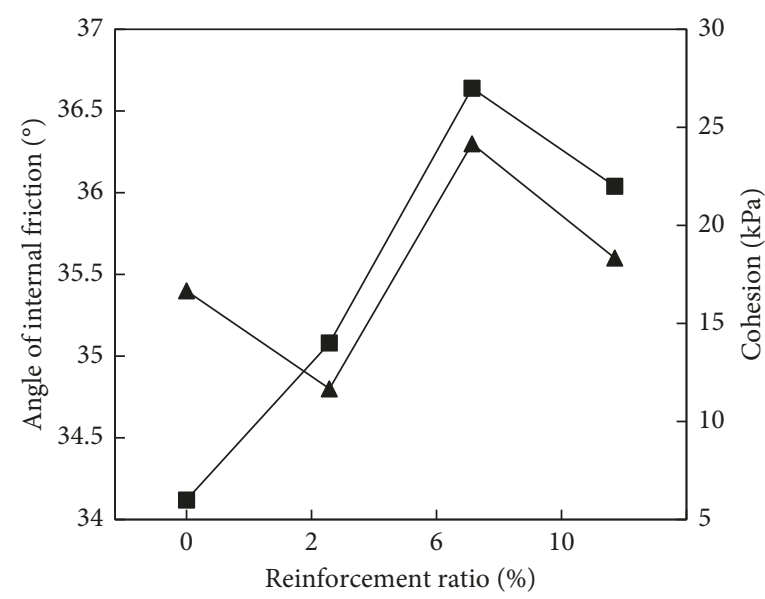

$\_$Angle of internal friction

$\rightarrow$ Cohesion

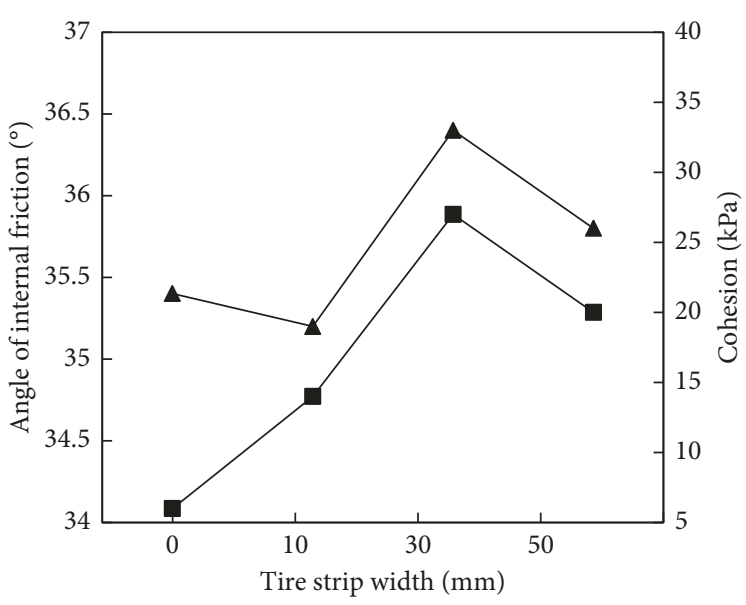

$\_$Angle of internal friction

- - Cohesion

(a)

(b)

FiguRE 8: Shear strength relationship between reinforced rate and width of tire strip.

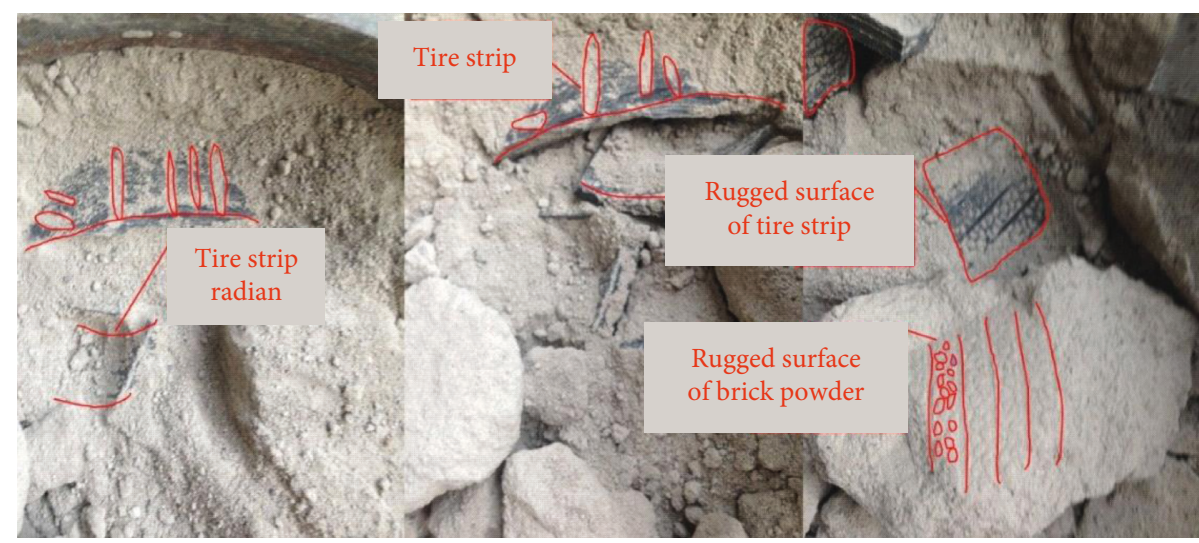

FIgURE 9: Tire strip and brick powder.

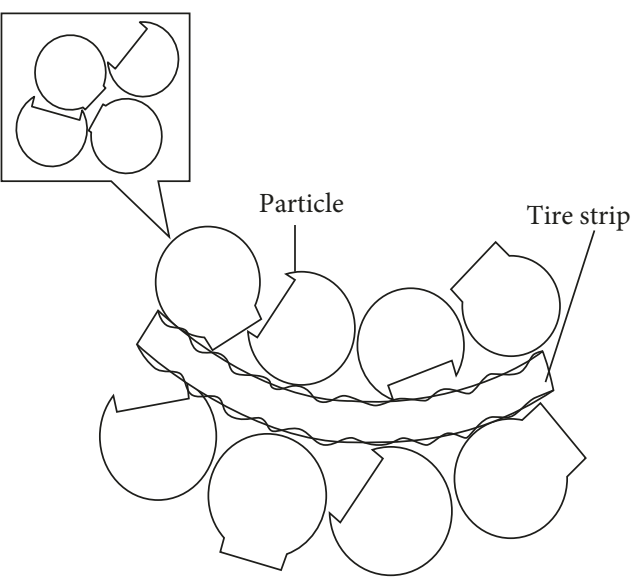

(a)

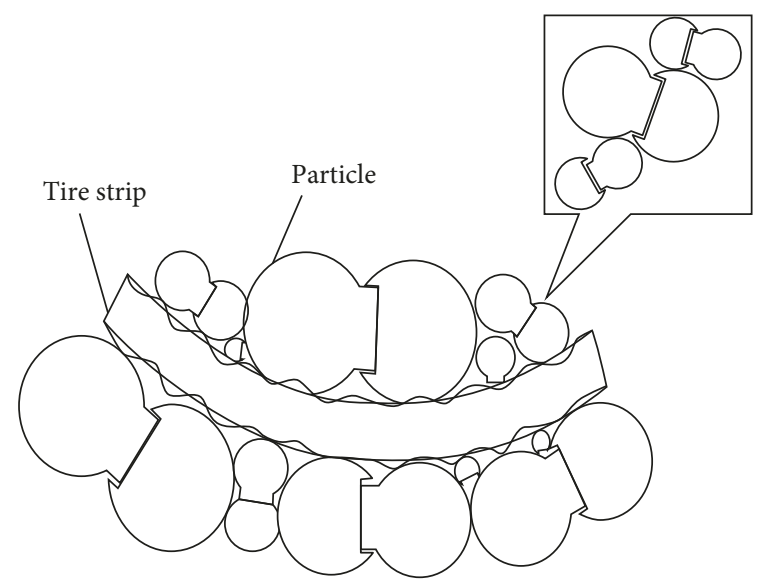

(b)

FIGURE 10: Changes of tire strips reinforced brick powder subjected to external load. 


\section{Conclusion}

In this paper, the shear mechanical properties of scrap tire strips reinforced brick powder are studied through a largescale direct shear test. It discusses the optimal reinforcement ratio and the stiffening size of the tire strip. And the action mechanism of scrap tire strips reinforced brick powder is considered. The main conclusions are as follows:

(i) The shear strength of the brick powder is enhanced by adding the tire strip. And the peak value of shear stress increases with the increase of vertical load. The residual shear strength of the specimen is also increased, and the deformation resistance of the specimen is enhanced. Under low vertical loads $(50 \mathrm{kPa}$ and $100 \mathrm{kPa})$ and high vertical load $(1600 \mathrm{kPa})$, the peak growth rate is not ideal compared with pure brick powder. The peak growth rate of shear stress decreases first, then increases, and at last decreases with the increase of vertical load.

(ii) The vertical load will also influence the reinforcement effect of the tire strip. If the vertical load is too small or too big, the shear strength of the specimen will be weakened when the tire strips are added. At the vertical load of $400 \mathrm{kPa}$, and the reinforcement ratio of $6 \%$, the reinforcement effect was best, and the peak shear stress increases by $23.7 \%$.

(iii) The reinforcement ratio and width of the scrap tire strips have little effect on the internal friction angle of the reinforced brick powder, but great effect on the cohesion. The reinforcement effect of the tire strips increases first and then decreases with the increase of the reinforcement ratio and width. The reinforcement effect is best at the $6 \%$ reinforcement ratio. At this reinforcement ratio, the tire strips with the width of $30 \mathrm{~mm}$ are better than that of $10 \mathrm{~mm}$ and $50 \mathrm{~mm}$ in reinforcement.

(iv) After adding the tire strips, the maximum vertical displacement decreases; however, the vertical displacement increases with the increase of vertical load. And the compression modulus and strain are different. The result is that the tire strips restrict the vertical displacement of the specimen, the greater the vertical load, the more obvious reduction of the vertical displacement of the reinforcement relative to the pure brick powder.

\section{Data Availability}

The corresponding author confirms that all of the content, figures (drawings, charts, photographs, etc.), and tables in the submitted work are either original work created by the authors listed in the manuscript or work for which permission to reuse has been obtained from the creator. The data used to support the findings of this study are available from the corresponding author upon request, and the readers can access the data supporting the conclusions of the study.

\section{Conflicts of Interest}

The authors declare that they have no conflicts of interest.

\section{Acknowledgments}

This work was supported by grants from the National Natural Science Foundation of China (NSFC) (no. 51678223) and Green Industrial Project of Hubei University of Technology (YXQN2017001). The authors would like to express their appreciation to these financial assistances.

\section{References}

[1] J.-W. Jang, T.-S. Yoo, J.-H. Oh, and I. Iwasaki, "Discarded tire recycling practices in the United States, Japan and Korea," Resources, Conservation and Recycling, vol. 22, no. 1-2, pp. 1-14, 1998.

[2] B. K. Huat, A. A. Aziz, and W. C. Loh, "Application of scrap tires as earth reinforcement for repair of tropical residual soil slope," Electronic Journal of Geotechnical Engineering, vol. 13, pp. 1-9, 2008.

[3] J. K. Kim and S. H. Lee, "New technology of crumb rubber compounding for recycling of waste tires," Journal of Applied Polymer Science, vol. 78, no. 8, pp. 1573-1577, 2015.

[4] M. A. Aiello and F. Leuzzi, "Waste tyre rubberized concrete: properties at fresh and hardened state," Waste Management, vol. 30 , no. 8-9, pp. 1696-1704, 2010.

[5] B. Acevedo, C. Barriocanal, I. Lupul, and G. Gryglewicz, "Properties and performance of mesoporous activated carbons from scrap tyres, bituminous wastes and coal," Fuel, vol. 151, no. 2, pp. 83-90, 2015.

[6] K. M. Ravi and G. Gourav, "Sustainable application of waste tire chips and geogrid for improving load carrying capacity of granular soils," Journal of Cleaner Production, vol. 200, pp. 542-551, 2018.

[7] T. Zhang, G. J. Cai, and W. H. Duan, "Strength and microstructure characteristics of the recycled rubber tire-sand mixtures as lightweight backfill," Environmental Science and Pollution Research, vol. 25, no. 4, pp. 3872-3883, 2017.

[8] Y. W. Yoon, S. H. Cheon, and D. S. Kang, "Bearing capacity and settlement of tire-reinforced sands," Geotextiles and Geomembranes, vol. 22, no. 5, pp. 439-453, 2004.

[9] K. S. Kim, Y. W. Yoon, and G. L. Yoon, "Pullout behavior of cell-type tires in reinforced soil structures," KSCE Journal of Civil Engineering, vol. 15, no. 7, pp. 1209-1217, 2011.

[10] L. H. Li, H. L. Xiao, J. J. Zheng et al., "Model test study on reinforced embankment slope with waste tire," Engineering Mechanics, vol. 32, no. 11, pp. 79-85, 2015.

[11] S. N. M. Tafreshi and A. H. Norouzi, "Bearing capacity of a square model footing on sand reinforced with shredded tire-an experimental investigation," Construction and Building Materials, vol. 35, pp. 547-556, 2012.

[12] Z. F. Zheng, S. Y. Liu, G. H. Cai, and Q. B. Wei, "Research progress of waste tire in road engineering," China Civil Engineering Journal, vol. s2, pp. 361-368, 2015.

[13] J. He, Y. Li, and X. C. Ruan, "Strength properties of waste tire rubber powder clay mixed soil," Chinese Journal of Rock Mechanics and Engineering, vol. s2, pp. 4366-4372, 2015, in Chinese.

[14] G. J. Foose, C. H. Benson, and P. J. Bosscher, "Sand reinforced with shredded waste tires," Journal of Geotechnical Engineering, vol. 122, no. 9, pp. 760-767, 1996. 
[15] M. Ghazavi and M. A. Sakhi, "Influence of optimized tire shreds on shear strength parameters of sand," International Journal of Geomechanics, vol. 5, no. 1, pp. 58-65, 2005.

[16] N. Hataf and M. M. Rahimi, "Experimental investigation of bearing capacity of sand reinforced with randomly distributed tire shreds," Construction and Building Materials, vol. 20, no. 10, pp. 910-916, 2006.

[17] S. Youwai and D. T. Bergado, "Numerical analysis of reinforced wall using rubber tire chips-sand mixtures as backfill material," Computers and Geotechnics, vol. 31, no. 2, pp. 103-114, 2004.

[18] H. Hazarika, J. Otani, and Y. Kikuchi, "Evaluation of tyre products as ground improving geomaterials," Proceedings of the Institution of Civil Engineers-Ground Improvement, vol. 165, no. 4, pp. 267-282, 2012.

[19] N. Cristelo, C. S. Vieira, and M. de Lurdes Lopes, "Geotechnical and geoenvironmental assessment of recycled construction and demolition waste for road embankments," Procedia Engineering, vol. 143, pp. 51-58, 2016.

[20] C. Settari, F. Debieb, E. H. Kadri, and O. Boukendakdji, "Assessing the effects of recycled asphalt pavement materials on the performance of roller compacted concrete," Construction and Building Materials, vol. 101, pp. 617-621, 2015.

[21] P. S. Martínez, M. G. Cortina, F. F. Martínez, and A. R. Sánchez, "Comparative study of three types of fine recycled aggregates from construction and demolition waste (CDW), and their use in masonry mortar fabrication," Journal of Cleaner Production, vol. 118, pp. 162-169, 2016.

[22] J. R. Zhang, C. Hu, Z. H. Sheng et al., "Experimental study on compaction characteristics of construction waste clay mixture," Rock and Soil Mechanics, vol. s2, pp. 349-355, 2016.

[23] P. Rosalía, C. Elena, E. Félix, and V. Fernando, "Fatigue performance of waste rubber concrete for rigid road pavements," Construction \& Building Materials, vol. 176, pp. 539-548, 2018.

[24] T. Park, "Application of construction and building debris as base and subbase materials in rigid pavement," Journal of Transportation Engineering, vol. 129, no. 5, pp. 558-563, 2003.

[25] R. Herrador, P. Pérez, L. Garach, and J. Ordóñez, "Use of recycled construction and demolition waste aggregate for road course surfacing," Journal of Transportation Engineering, vol. 138, no. 2, pp. 182-190, 2012.

[26] J. R. Jiménez, J. Ayuso, A. P. Galvín, M. López, and F. Agrela, "Use of mixed recycled aggregates with a low embodied energy from non-selected CDW in unpaved rural roads," Construction and Building Materials, vol. 34, pp. 34-43, 2012.

[27] L. Delongui, M. Matuella, W. P. Núñez, W. Fedrigo, L. C. P. D. Silva Filho, and J. A. P. Ceratti, "Construction and demolition waste parameters for rational pavement design," Construction and Building Materials, vol. 168, pp. 105-112, 2018.

[28] C. G. Bao, M. Y. Wang, and J. H. Ding, "Mechanism of soil reinforced with geogrid," Journal of Yangtze River Scientific Research Institute, vol. 30, no. 1, pp. 34-41, 2013.

[29] C. G. Bao, J. H. Ding, and M. Y. Wang, "Review on limited balance theory applied in the design of reinforced soil structures," Journal of Yangtze River Scientific Research Institute, vol. 31, no. 3, pp. 1-10, 2014.

[30] Y. M. Zhang, X. D. Zhang, and H. R. Zhang, "Test research of geotechnique textile soil reinforcement mechanism and engineering application," Rock and Soil Mechanics, vol. 26, no. 8, pp. 1323-1326, 2016. 


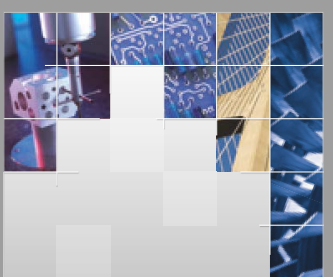

\section{Enfincering}
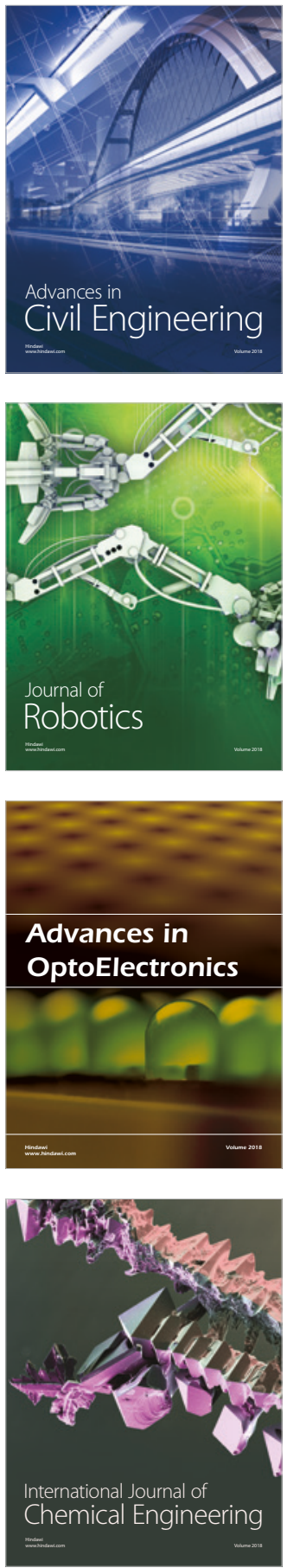

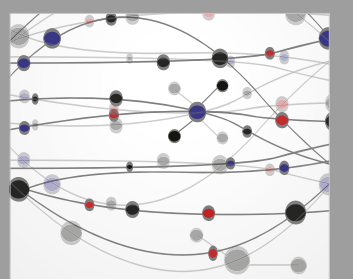

\section{Rotating \\ Machinery}

The Scientific World Journal

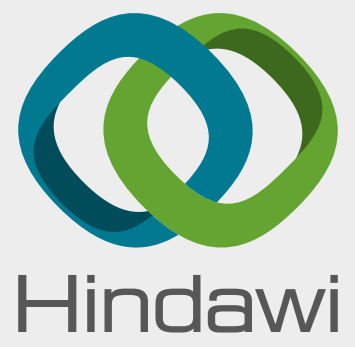

Submit your manuscripts at

www.hindawi.com
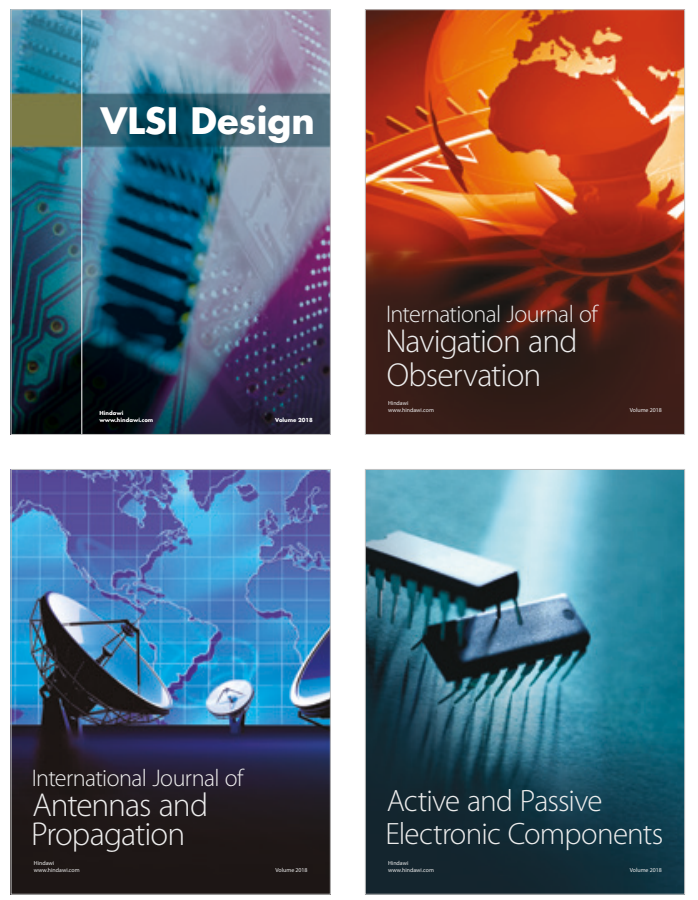
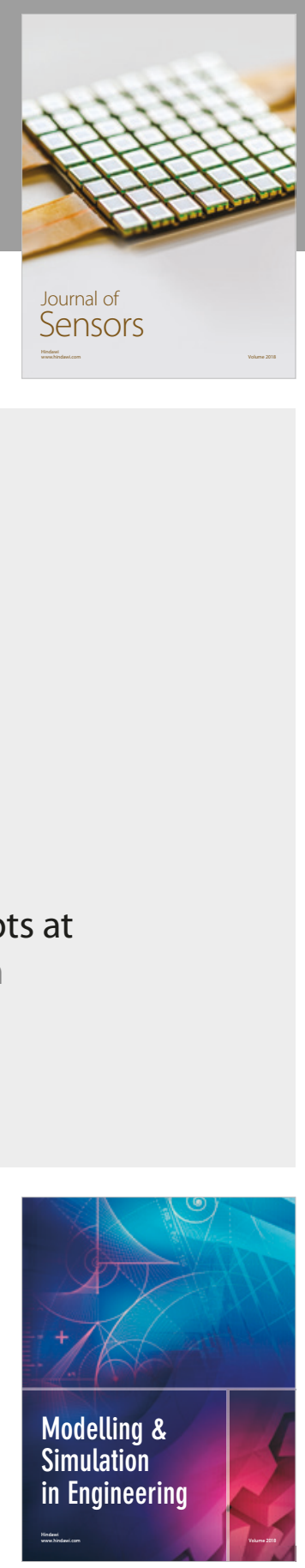

\section{Advances \\ Multimedia}
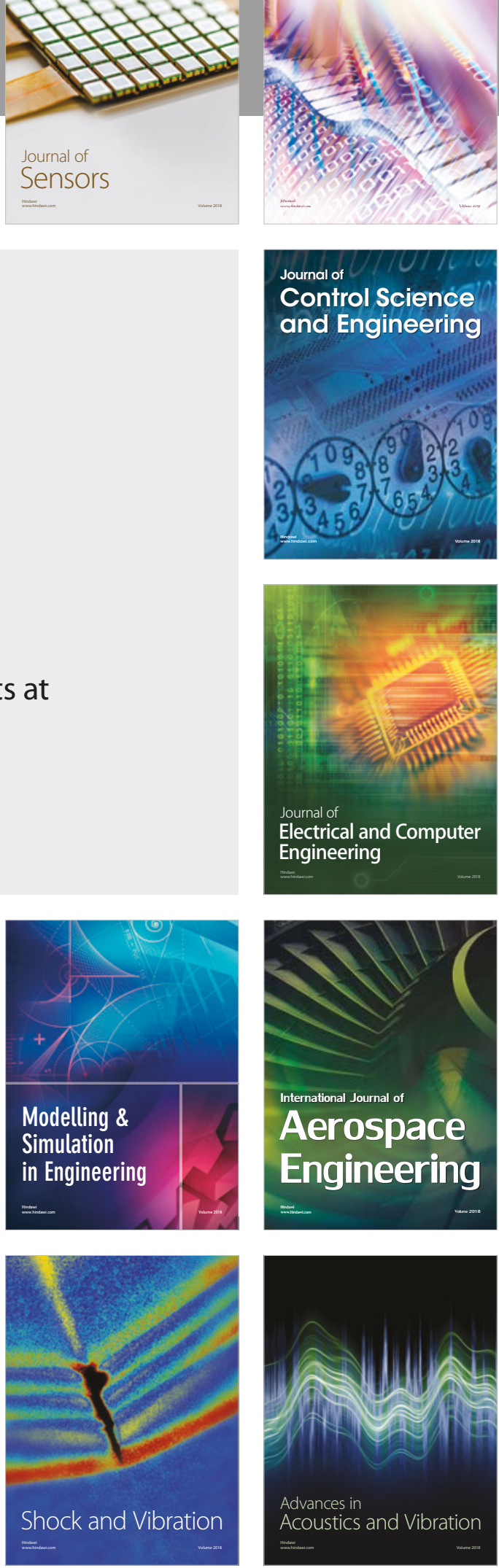